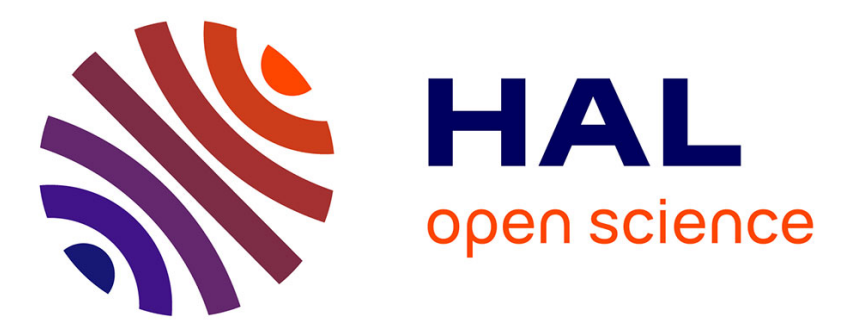

\title{
Intra- and Interobserver Reliability of Ultrasound Measurement of the Plantar Fascia.
}

Michael Skovdal Rathleff, Carsten Møller Mølgaard, Jens Lykkegaard Olesen

\section{To cite this version:}

Michael Skovdal Rathleff, Carsten Møller Mølgaard, Jens Lykkegaard Olesen. Intra- and Interobserver Reliability of Ultrasound Measurement of the Plantar Fascia.. Journal of Clinical Ultrasound, 2011, 39 (3), pp.128. 10.1002/jcu.20787 . hal-00613769

\section{HAL Id: hal-00613769 \\ https://hal.science/hal-00613769}

Submitted on 6 Aug 2011

HAL is a multi-disciplinary open access archive for the deposit and dissemination of scientific research documents, whether they are published or not. The documents may come from teaching and research institutions in France or abroad, or from public or private research centers.
L'archive ouverte pluridisciplinaire HAL, est destinée au dépôt et à la diffusion de documents scientifiques de niveau recherche, publiés ou non, émanant des établissements d'enseignement et de recherche français ou étrangers, des laboratoires publics ou privés. 
Journal of Clinical Ultrasound

WILEY

\section{Intra- and Interobserver Reliability of Ultrasound Measurement of the Plantar Fascia.}

\begin{tabular}{|r|l|}
\hline Journal: & Journal of Clinical Ultrasound \\
\hline Manuscript ID: & JCU-10-091.R1 \\
\hline Wiley - Manuscript type: & Research Article \\
\hline Keywords: & foot, musculoskeletal, plantar fascia, Plantar fasciitis, sonography \\
\hline \multicolumn{2}{|}{} \\
\hline
\end{tabular}

\section{SCHOLARONE ${ }^{\text {M }}$ \\ Manuscripts}


Ultrasound Measurement of the plantar fascia

Intra- and Interobserver Reliability of Ultrasound Measurement of the Plantar Fascia.

2

3

7

8

9

10

11

12

13

14

15

16

17

18

19

20

21

22

23

24

25

26

27

28

29

30

31

32

33

34

35

36

37

38

39

40

41

42

43

44

45

46

47

48

49

50

51

52

53

54

55

56

57

58

59

60 
Ultrasound Measurement of the plantar fascia

\begin{abstract}
Purpose

To determine intra- and interobserver reliability and measurements precision of Ultrasound Imaging (US) assessment of plantar fascia thickness when using one, the mean of two or three measurements..

\section{Methods}

Two experienced observers scanned 20 healthy subjects twice with 60 minutes between test and retest. A GE LOGIQe ultrasound scanner was used in the study. The built-in software in the scanner was used to measure the thickness of the plantar fascia (PF). Reliability was calculated using intraclass correlation coefficient (ICC) and limits of agreement (LOA).

\section{Results}

Intraobserver reliability using one sonogram was ICC 0.50 and 0.52 , and using the mean of three sonograms intraobserver reliability increased up to 0.77 . Interobserver reliability when measuring one sonogram was ICC 0.62 and increased to 0.82 when using the average of three sonograms. LOA showed that when using the average of 3 sonograms, LOA decreased to $0.6 \mathrm{~mm}$, corresponding to $17.5 \%$ of the mean thickness of the PF.
\end{abstract}

\title{
Conclusions
}

The results showed that reliability increases when using the mean of three sonograms compared to one. Limits of agreement based on intratester reliability shows that changes in thickness that are larger than $0.6 \mathrm{~mm}$ can be considered actual changes in thickness and not a result of measurement error.

Keywords: foot; musculoskeletal; plantar fascia; plantar fasciitis; reliability;sonography 
Ultrasound Measurement of the plantar fascia

\section{Introduction}

Ultrasound imaging (US) is a well-established, non-invasive method for examining soft tissue structures of the foot, including the plantar fascia (PF). ${ }^{1,2}$ It is a valuable tool in clinical practice to evaluate the integrity of musculoskeletal structures qualitatively ${ }^{3,4}$. Healthy tendons are known to have a well-organized, uniform, hyperechoic pattern of collagen. ${ }^{5}$ Conversely, tendons with pathology is often thicker and have a more disorganized, diffuse or hypoechoic appearance on US. ${ }^{1,4}$ In essence, tendon health can be clinically evaluated by recording a grayscale sonogram of the tendon.

Diagnosis of plantar fasciitis is often made due to a combination of patient complaints, localization of pain and measurable thickening of the PF. This has been reported in case control studies where patients with plantar fasciitis was compared to healthy subjects. ${ }^{2,7}$ Interestingly a correlation has been seen between a reduction in the thickness of the PF and a reduction in pain. ${ }^{8}$

Ultrasonography is often used to support the diagnosis of plantar fasciitis by measuring a thickening of the PF. During rehabilitation US may also be used to secure that rehabilitation is proceeding as expected. The goal during rehabilitation is to observe a reduction in the thickness of the PF as well as a reduction in pain. The main problem with US is that it is a real-time and operator-dependent technique, and factors such as transducer-handling and machine-settings might influence size and appearance of the PF. If patients are examined several times by different examiners, it is essential to know intraobserver and interobserver reliability and precision of the method. This will allow the examiner to know if the changes observed are actual changes in thickness or a result of measurement error. To our knowledge, inter- and intraobserver reliability of US assessment of PF thickness and intra-day variation in the thickness of the PF are not yet known. 
$<20 \%)$.
Methods
Participants

$<20 \%)$.
Methods
Participants

Twenty healthy volunteers, aged 20 to 31 years, without lower extremity symptoms, were recruited for this study. Exclusion criteria were prior history of surgery to the foot and current or prior pain in PF. Participants provided consent on forms approved by the local Ethics Committee in Denmark (N-2009-0050).

Examiners

Two experienced observers were recruited for the study. Both had used musculoskeletal US as part of daily examinations for 2-5 years. In order to minimize learning effect from customization to the specific US machine used in the study, both examiners were allowed a recommendation period of 4 sessions with the US machine.

Test

Measurements were carried out using the set of recommendations from the ESSR (European Society of Musculoskeletal Radiology), figure 1. ${ }^{9}$ Subjects were positioned in a prone position. The toes were dorsally flexed, and the talo-crural joint was positioned in 0 degrees. As the PF is 
Ultrasound Measurement of the plantar fascia

attached at the plantar surface at the toes, dorsal flexion of the toes creates tension in the PF and makes the borders of the fascia more clearly defined. The transducer was placed over the plantar aspect of the hindfoot to examine the PF at the insertion onto the calcaneus. Long-axis sonograms were obtained approximately $0.5 \mathrm{~cm}$ medial to the midline of the plantar surface of the foot, figure 2. Sonograms of both the right and the left foot were used in the study. The scanner was from General Electric Healthcare (3135 Easton Tpke, Fairfield, CT, USA), model LOGIQ e. The transducer that was used was a 12L RS, $13 \mathrm{MHz}$ linear transducer. Scan depth was set to $2 \mathrm{~cm}$. Three successive scans were made of each foot to resemble a feasible clinical setting. Between each scan the transducer was moved away from the foot and then repositioned. It was decided at random whether observer 1 or 2 did the first scan and whether the scans were initiated on the left or the right foot. To investigate whether the two examiners would increase reliability during the day of testing, all subjects received a consecutive identification number. This allowed us to ensure that no learning effect would influence the results.

Figure 1 about here.

Figure 2 about here.

Retest

After a period of approximately 60 minutes, the subjects underwent a second ultrasound examination. During the retest, three additional sonograms of the PF were recorded. Care was taken to maintain the same standardized foot position, to keep the ultrasound machine settings constant, and to replicate the exact measurement. As physical activity and time-of-day might influence on the actual thickness of the PF, we chose a period of 60 minutes between test and retest. ${ }^{9,10}$ All subjects where instructed to rest between test and retest. 
Ultrasound Measurement of the plantar fascia

\section{Sonogram Analysis}

All sonograms were measured using the built-in software in the scanner. PF thickness measurements were made at the insertion onto the calcaneus. A third person randomly loaded sonograms onto the screen for examiner 1 and 2 to measure, thereby blinding the observers to which subject they were measuring.

\section{Data Analysis}

Statistical analysis was performed using SPSS version 15.0. The dependant measure of PF thickness was calculated using the built-in software in the scanner. Each sequential measurement was arranged in SPSS as a separate variable, and intraexaminer reliability with $95 \%$ confidence intervals (CI) was estimated using two-way mixed-model, consistency-type intraclass correlation coefficients (ICC).

Both examiners were blinded during measurement of the current and previous thickness values. The reliability when using a single measurement was estimated using the first 2 measurement variables and the "single measures" output from SPSS. The reliability when using a mean of 2 measurements was estimated using the first 2 measurement variables and the "average measures" output from SPSS. The reliability when using a mean of 3 measurements was similarly estimated using the first 3 measurement variables and the "average measures" output from SPSS. To determine interobserver reliability, a parallel model (two-way random effect, total agreement) with single measurement and mean values of 2 and 3 measurements was calculated.

\footnotetext{
Measurement precision was assessed by limits of agreement (LOA) and LOA as a percentage of the mean value (LOA\%).
} 
Ultrasound Measurement of the plantar fascia

\section{Results}

The sample included in the study consisted of 4 men and 16 women. Mean age was 24.1 (SD 2.6).

Mean body mass index (BMI) was 22.2 (SD 2.1).

Paired t-test shows no significant difference between the right and left PF, ( $p>0.05)$, table 1. Paired t-test shows no systematic difference in thickness between test and retest for observer 1 or observer $2(\mathrm{p}>0.05)$. ICC values show no significant difference in reliability between right and left PF which is the reason why the right and left plantar fascias are pooled in the reliability analysis.

Table 1

\section{Intraobserver}

Intraobserver reliability measured by ICC for observer 1 using one sonogram was 0.50 (CI 0.230.70 ) and increased to 0.77 (CI $0.56-0.87$ ) when using the average of three sonograms. Intraobserver reliability for observer 2 using one sonogram was 0.52 (CI 0.09-0.75) and increased to 0.67 (CI 0.39-0.82) when using the average of three sonograms. When using one sonogram, LOA was $0.8 \mathrm{~mm}$ for observer 1 and 0.9 for observer 2. LOA decreased to $0.6 \mathrm{~mm}$ (LOA\% of $17.5 \%$ ) and $0.8 \mathrm{~mm}$ (LOA\% 20.8) when using the mean of three sonograms, table 2.

Table 2

\section{Interobserver}

Interobserver reliability when measuring different sonograms measured by ICC was 0.62 (CI 0.370.78 ) and increased to 0.82 (CI 0.65-0.91) when using the mean of three sonograms, table 3 . When the observers measured the same set of sonograms, reliability measured by ICC was 0.71 (CI 0.500.84 ) and 0.73 (CI 0.55-0.85) and increased to 0.89 (CI 0.78-0.95) and 0.91 (CI 0.82-0.95) Table 3 
Ultrasound Measurement of the plantar fascia

Doing a visual inspection of the consecutive ID number plotted against the difference between test and retest, there are no sign of learning effect with decreased difference with increasing ID number. Furthermore a Bland-Altman plot with the difference between test and retest plotted against the thickness of the PF shows no sign of increased error with increased thickness of the PF.

\section{Discussion}

The purpose of this study was to determine the intra- and interobserver reliability of US assessment of PF thickness and to investigate improvements in measurement precision when using the mean value of three measurements compared to one. Intraobserver reliability using one sonogram was 0.50 and 0.52 and using the mean of three sonograms intraobserver reliability increased to 0.67 and 0.77. Interobserver reliability when using one sonogram was 0.62 and increased to 0.82 when using the average of three sonograms. LOA based on intratester reliability shows that changes in thickness that are larger than $0.8 \mathrm{~mm}$ can be considered actual changes in thickness and not a result of measurement error.

A study by Liang et al $^{12}$ examined the intraobserver reliability of US to assess the thickness of fascia plantaris in 14 patients diagnosed with plantar fasciitis. They showed ICC values of 0.90 (CI 0.70-0.97). Craig et $\mathrm{al}^{13}$ did a similar study on an unknown number of patients with diabetes and found ICC of 0.89 . Neither Liang et $\mathrm{al}^{12}$ or Craig et $\mathrm{al}^{13}$ reported whether the measurements were done by a blinded observer, how long time there was between test and retest or which ICC model was used. This makes a direct comparison difficult.

\section{Intraobserver reliability}


Ultrasound Measurement of the plantar fascia

Koppenhaver ${ }^{14}$ examined the intraobserver reliability US to assess the thickness of transverses abdominis (TrA) and multifidi (MU) with a study design similar to this. They found ICC values of 0.83 (CI 0.67-0.91) and 0.79 (CI 0.61-0.81), corresponding to $15.1 \%$ and $19.1 \%$ Standard Error of the Estimate (SEM), which approximately corresponds to LOA of $0.7 \mathrm{~mm}$ and $0.9 \mathrm{~mm}$. SEM and LOA are comparable if study designs are similar. ${ }^{15}$ Springer et al ${ }^{16}$ did a similar study where they found a intraobserver SEM of $17 \%$ when measuring the thickness of TrA, corresponding to measurements precision of $1.3 \mathrm{~mm}$. Bjordal ${ }^{17}$ examined intraobserver reliability when measuring the thickness of the tendon from m supraspinatus. They found LOA of $0.4 \mathrm{~mm}$ and a mean value of tendon thickness of $6.6 \mathrm{~mm}$.

\section{Interobserver reliability}

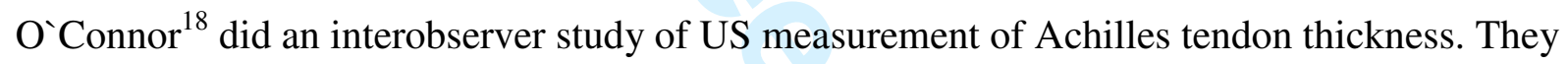
found a LOA\% of $29 \%$. Ying ${ }^{19}$ did a similar study and found interobserver measurement error between 5 observers of $0.9-1.1 \mathrm{~mm}$, which corresponds to a LOA\% of approximately $20 \%$.

It appears that intraobserver reliability of US assessments of human tendon and muscle thickness are between $0.4 \mathrm{~mm}$ and $1.3 \mathrm{~mm}$ when measuring healthy tendons. LOA\% is between 15 and $19 \%$. Interobserver reliability is slightly lower with LOA\% of approximately $20 \%$. We found intraobserver reliability of ICC 0.77 and 0.67 and LOA $0.6 \mathrm{~mm}$ and $0.8 \mathrm{~mm}$, corresponding to $17.5 \%$ and $20.8 \%$. Interobserver reliability was ICC 0.82 , LOA 0.57 , corresponding to $15.8 \%$. Both intra- and interobserver reliability found in the literature correspond to the findings in this study.

\section{Clinical Relevance}




\section{Limitations of ICC}

In order to analyze intra- and interobserver reliability, we used ICC and LOA. ICC is a very common method for describing reliability in different settings. However ICC has some limitations. The size of ICC depends on the ratio of the variability between subjects to the total variability. ${ }^{18}$ This means that the size of ICC may be affected by factors related to the study sample itself. ${ }^{18}$ If two separate test-retest studies are performed on two study samples where one study sample consists of a homogenous group and the other consists of a very heterogeneous groups, the results will be different. This is not because the methods being used have different reliability in the two groups, but because ICC is dependent on the ratio of the variability between subjects to the total variability. ${ }^{18}$ The higher ICC in a heterogeneous group is due to the calculations that ICC is based on and not due to the fact that the methods in the two study samples disagree. The consequence is that it is easier to disguise measurement error in a heterogeneous population. Liang et $\mathrm{al}^{12}$ and Craig et $\mathrm{al}^{13}$ both examined pathological groups that may consist of a more heterogeneous sample. This 
Ultrasound Measurement of the plantar fascia

may explain why the LOA found in the current study corresponds to other studies, but ICC in the current study is lower than what was reported by Liang et $\mathrm{al}^{12}$ and Craig et al. ${ }^{13}$

\section{Comparison of mean thickness of the PF}

The earliest study where the thickness of the Pf was quantified by US was published in $1993 .{ }^{21}$ Studies that examine healthy subjects find mean values of the thickness between 2.6 and $3.9 \mathrm{~mm}$. ${ }^{21-27}$ The two largest studies, which included 154 and 110 subjects, found mean thickness of the PF of $3.2 \mathrm{~mm}$ (women and men combined) and $3.3 \mathrm{~mm}( \pm 0.3 \mathrm{~mm})$ for women and $3.9 \mathrm{~mm}( \pm 0.5 \mathrm{~mm})$ for men. The average values in these studies are very similar to the ones found in the present study. Discrepancy in the positioning of subjects, different reference point of measurement and body mass index may to some extent explain the variation from 2.6 to $3.9 \mathrm{~mm}$.

\section{Largest measurement error from scan or measurement}

The results in table 2 and 3 show that the interobserver reliability when both observers measure the same scans is higher than when they measure separate scans. This indicates that scan is a source of error rather than measurement of the scan. The thickness of the PF is not identical across the entire insertion onto the calcaneus. ${ }^{28}$ This means that movement of the transducer might affect the recorded thickness. Furthermore it indicates that some of the variance across the different scan is not only due to measurement error, but reflects actual changes in thickness.

\section{Conclusion}

Measurement of PF thickness by US is a reliable method. If the same observer measures the same person twice, the difference will be maximum $0.6-0.8 \mathrm{~mm}$ (ICC $0.67-0.77$ ) in $95 \%$ of the examinations when using the mean of three sonograms. If two different observers examine the same 
Ultrasound Measurement of the plantar fascia

subject twice, the measurement error will be maximum $0.6 \mathrm{~mm}$ (ICC 0.82) in $95 \%$ of the examinations. 
Ultrasound Measurement of the plantar fascia

\section{Reference List}

1. Fornage BD, Rifkin MD Ultrasound examination of the hand and foot. Radiol Clin North Am 1988; 26: 109-129

2. Cardinal E, Chhem RK, Beauregard CG, et al. Plantar fasciitis: sonographic evaluation. Radiology 1996; 201: 257-259

3. Kannus P, Jozsa L Histopathological changes preceding spontaneous rupture of a tendon. A controlled study of 891 patients. J Bone Joint Surg Am 1991; 73: 1507-1525

4. Martinoli C, Bianchi S, Derchi LE Tendon and nerve sonography. Radiol Clin North Am 1999; 37: 691-711, viii

5. Fornage BD, Rifkin MD Ultrasound examination of tendons. Radiol Clin North Am 1988; 26: 87-107

6. McPoil TG, Martin RL, Cornwall MW, et al. Heel pain--plantar fasciitis: clinical practice guildelines linked to the international classification of function, disability, and health from the orthopaedic section of the American Physical Therapy Association. J Orthop Sports Phys Ther 2008; 38: A1-A18

7. Wearing SC, Smeathers JE, Sullivan PM, et al. Plantar fasciitis: are pain and fascial thickness associated with arch shape and loading? Phys Ther 2007; 87: 1002-1008

8. Hammer DS, Adam F, Kreutz A, et al. Ultrasonographic evaluation at 6-month follow-up of plantar fasciitis after extracorporeal shock wave therapy. Arch Orthop Trauma Surg 2005; $125: 6-9$ 
Ultrasound Measurement of the plantar fascia

9. Beggs, I, Bianchi, S, Bueno, A, and et al. Musculoskeletal Ultrasound Technical Guidelines: VI. Ankle. [First edition]. 2010. European Society of Musculoskeletal Radiology. Accesssed 19-8-2010 on www.essr.org/html/img/pool/ankle.pdf

10. Grigg NL, Stevenson NJ, Wearing SC, Smeathers JE Incidental walking activity is sufficient to induce time-dependent conditioning of the Achilles tendon. Gait Posture 2009 2010: 31(1):64-7.

11 Grigg NL, Wearing SC, Smeathers JE Eccentric calf muscle exercise produces a greater acute reduction in Achilles tendon thickness than concentric exercise. Br J Sports Med 2009; 43: 280-283

12. Liang HW, Wang TG, Chen WS, et al. Thinner plantar fascia predicts decreased pain after extracorporeal shock wave therapy. Clin Orthop Relat Res 2007; 460: 219-225

13. Craig ME, Duffin AC, Gallego PH, et al. Plantar fascia thickness, a measure of tissue glycation, predicts the development of complications in adolescents with type 1 diabetes. Diabetes Care 2008; 31: 1201-1206

14. Koppenhaver SL, Parent EC, Teyhen DS, et al. The effect of averaging multiple trials on measurement error during ultrasound imaging of transversus abdominis and lumbar multifidus muscles in individuals with low back pain. J Orthop Sports Phys Ther 2009; 39: 604-611

15. Atkinson G, Nevill A Typical error versus limits of agreement. Sports Med 2000; 30: 375381 
Ultrasound Measurement of the plantar fascia

16. Springer BA, Mielcarek BJ, Nesfield TK, et al. Relationships among lateral abdominal muscles, gender, body mass index, and hand dominance. J Orthop Sports Phys Ther 2006; 36: 289-297

17. Bjordal, JM, Demmink, JH, and Ljunggren AE. Tendon Thickness and Depth from Skin for Supraspinatus, Common Wrist and Finger Extensors, Patellar and Achilles Tendons: Ultrasonography study of healthy subjects. Phys.Ther. 89[6], 375-383. 2005.

18. O'Connor PJ, Grainger AJ, Morgan SR, et al. Ultrasound assessment of tendons in asymptomatic volunteers: a study of reproducibility. Eur Radiol 2004; 14: 19681973

19. Ying M, Yeung E, Li B, et al. Sonographic evaluation of the size of Achilles tendon: the effect of exercise and dominance of the ankle. Ultrasound Med Biol 2003; 29: 637642

20. Norman G The pruning of Doctor McDonough and the "humanizing" of statistics. Fertil Steril 1997; 68: 570-573

21. Wall JR, Harkness MA, Crawford A Ultrasound diagnosis of plantar fasciitis. Foot Ankle 1993; 14: 465-470

22. Vohra PK, Kincaid BR, Japour CJ, et al. Ultrasonographic evaluation of plantar fascia bands. A retrospective study of 211 symptomatic feet. J Am Podiatr Med Assoc 2002; 92: 444-449 
Ultrasound Measurement of the plantar fascia

23. Pascual HJ, Garcia JM, Matamoros EC, et al. Relationship of body mass index, ankle dorsiflexion, and foot pronation on plantar fascia thickness in healthy, asymptomatic subjects. J Am Podiatr Med Assoc 2008; 98: 379-385

24. Akfirat M, Sen C, Gunes T Ultrasonographic appearance of the plantar fasciitis. Clin Imaging 2003; 27: 353-357

25. Ozdemir H, Yilmaz E, Murat A, et al. Sonographic evaluation of plantar fasciitis and relation to body mass index. Eur J Radiol 2005; 54: 443-447

26. Genc H, Saracoglu M, Nacir B, et al. Long-term ultrasonographic follow-up of plantar fasciitis patients treated with steroid injection. Joint Bone Spine 2005; 72: 61-65

27. Sabir N, Demirlenk S, Yagci B, et al. Clinical utility of sonography in diagnosing plantar fasciitis. J Ultrasound Med 2005; 24: 1041-1048

28. Moraes do Carmo CC, Fonseca de Almeida Melao LI, et al. Anatomical features of plantar aponeurosis: cadaveric study using ultrasonography and magnetic resonance imaging. Skeletal Radiol 2008; 37: 929-935 
Ultrasound Measurement of the plantar fascia

Deleted: Quantitative

Intra- and Interobserver Reliability of Ultrasound Measurement of the Plantar Fascia.

Deleted: Human 
Ultrasound Measurement of the plantar fascia

\section{ABSTRACT}

Purpose

To determine intra- and interobserver reliability and measurements precision of Ultrasound Imaging (US) assessment of plantar fascia thickness when using one, the mean of two or three measurements.

Deleted: UI

\section{Methods}

Two experienced observers scanned 20 healthy subjects twice with 60 minutes between test and

retest. A GE LOGIQe ultrasound scanner was used in the study. The built-in software in the scanner

was used to measure the thickness of the plantar fascia (PF). Reliability was calculated using

Deleted: inbuilt

Deleted: diameter Deleted: PF intraclass correlation coefficient (ICC) and limits of agreement (LOA).

\section{Results}

Intraobserver reliability using one sonogram was ICC 0.50 and 0.52 , and using the mean of three sonograms intraobserver reliability increased up to 0.77 . Interobserver reliability when measuring one sonogram was ICC 0.62 and increased to 0.82 when using the average of three sonograms.

LOA showed that when using the average of 3 sonograms, LOA decreased to $0.6 \mathrm{~mm}$, corresponding to $17.5 \%$ of the mean thickness of the PF.

\section{Conclusions}

The results showed that reliability increases when using the mean of three sonograms compared to

Deleted: image

Deleted: diameter one. Limits of agreement based on intratester reliability shows that changes in thickness that are

Deleted: 3 larger than $0.6 \mathrm{~mm}$ can be considered actual changes in thickness and not a result of measurement Deleted: diameter error.

Keywords: foot; musculoskeletal; plantar fascia; plantar fasciitis; reliability;sonography 
Ultrasound Measurement of the plantar fascia

\section{Introduction}

Ultrasound imaging (US) is a well-established, non-invasive method for examining soft tissue structures of the foot, including the plantar fascia $(\underline{\mathrm{PF}}) .{ }^{1,2}$ It is a valuable tool in clinical practice to evaluate the integrity of musculoskeletal structures qualitatively ${ }^{3,4}$. Healthy tendons are known to

have a well-organized, uniform, hyperechoic pattern of collagen. ${ }^{5}$ Conversely, tendons with

pathology is often thicker and have a more disorganized, diffuse or hypoechoic appearance on US.

${ }^{1,4}$ In essence, tendon health can be clinically evaluated by recording a grayscale sonogram of the tendon.

Diagnosis of plantar fasciitis is often made due to a combination of patient complaints, localization of pain and measurable thickening of the PF. This has been reported in case control studies where patients with plantar fasciitis was compared to healthy subjects. ${ }^{2,7}$ Interestingly a correlation has been seen between a reduction in the thickness of the PF and a reduction in pain. ${ }^{8}$

\begin{tabular}{|l|}
\hline Deleted: as \\
Deleted: between \\
Deleted: plantar fascia \\
\hline Deleted: PF \\
Deleted: are \\
Deleted: diameter \\
Deleted: plantar fascia \\
\hline
\end{tabular}

Ultrasonography is often used to support the diagnosis of plantar fasciitis by measuring a thickening of the PF. During rehabilitation US may also be used to secure that rehabilitation is proceeding as expected. The goal during rehabilitation is to observe a reduction in the thickness of the PF as well as a reduction in pain. The main problem with $U S$ is that it is a real-time and operator-dependent technique, and factors such as transducer-handling and machine-settings might influence size and appearance of the PF. If patients are examined several times by different examiners, it is essential to know intraobserver and interobserver reliability and precision of the method. This will allow the examiner to know if the changes observed are actual changes in thickness or a result of measurement error. To our knowledge ${ }_{2}$ inter- and intraobserver reliability of $\mathrm{US}$ assessment of PF thickness and intra-day variation in the thickness of the PF are not yet known.

Deleted: plantar fascia

Deleted: As UI is an integrated part of
the diagnosis and evaluation of treatment
success, patients are often examined
several times to control if rehabilitation is
proceeding as expected.
Deleted: diameter
Deleted: plantar fascia
Deleted: UI
Deleted: can
Deleted: plantar fascia

Deleted: diameter

\begin{tabular}{|l|}
\hline Deleted: UI \\
\hline Deleted: plantar fascia \\
Deleted: diameter \\
Deleted: plantar fascia \\
Deleted: is
\end{tabular}


Ultrasound Measurement of the plantar fascia

The purpose of the study is to determine intra- and interobserver reliability and measurement precision of US assessment of PF thickness when using one or the average of multiple scans. We expected that intraobserver reliability would be higher than interobserver reliability and that both inter- and intraobserver reliability would increase if the mean of three measurements was used.

Overall we expected that through a standardized protocol in which one examiner records and measures three sonograms, US will be reliable (ICC $>0.75$ ) and precise (Limits of agreement $<20 \%)$.

\section{Methods}

Participants

Twenty healthy volunteers, aged 20 to 31 years, without lower extremity symptoms, were recruited

for this study. Exclusion criteria were prior history of surgery to the foot and current or prior pain in

PF. Participants provided consent on forms approved by the local Ethics Committee in Denmark (N-2009-0050).

Examiners

Two experienced observers were recruited for the study. Both had used musculoskeletal US as part of daily examinations for $2-5$ years. In order to minimize learning effect from customization to the specific US machine used in the study, both examiners were allowed a recommendation period of 4 sessions with the US machine,

Test

Measurements were carried out using the set of recommendations from the ESSR (European

Society of Musculoskeletal Radiology), figure $1 .{ }^{9}$ Subjects were positioned in a prone position. The toes were dorsally flexed ${ }_{2}$ and the talo-crural joint was positioned in 0 degrees. As the PF is
Deleted: s

Deleted: UI

Deleted: plantar fascia

Deleted: wil

\begin{tabular}{|l|}
\hline Deleted: have \\
\hline Deleted: been using \\
\hline Deleted: UI \\
\hline Deleted: \\
\hline Deleted: between \\
Deleted: and \\
Deleted: serior to testing \\
\hline Deleted: UI \\
Deleted: used in the study.
\end{tabular}

Deleted: plantar fascia 
Ultrasound Measurement of the plantar fascia

attached at the plantar surface at the toes, dorsal flexion of the toes creates tension in the PF and makes the borders of the fascia more clearly defined. The transducer was placed over the plantar aspect of the hindfoot to examine the PF at the insertion onto the calcaneus. Long-axis sonograms were obtained approximately $0.5 \mathrm{~cm}$ medial to the midline of the plantar surface of the foot, figure 2. Sonograms of both the right and the left foot were used in the study. The scanner was from General Electric Healthcare (3135 Easton Tpke, Fairfield, CT, USA), model LOGIQ e. The transducer that was used was a 12L RS, $13 \mathrm{MHz}$ linear transducer. Scan depth was set to $2 \mathrm{~cm}$.

Three successive scans were made of each foot to resemble a feasible clinical setting. Between each scan the transducer was moved away from the foot and then repositioned. It was decided at random, whether observer 1 or 2 did the first scan and whether the scans were initiated on the left or the right foot. To investigate whether the two examiners would increase reliability during the day of testing, all subjects received a consecutive identification number. This allowed us to ensure that no learning effect would influence the results.

Figure 1 about here.

Figure 2 about here.

Retest

After a period of approximately 60 minutes, the subjects underwent a second ultrasound examination. During the retest, three additional sonograms of the PF were recorded. Care was taken to maintain the same standardized foot position, to keep the ultrasound machine settings constant, and to replicate the exact measurement. As physical activity and time-of-day might influence on the actual thickness of the PF, we chose a period of 60 minutes between test and retest. ${ }^{9,10}$ All subjects where instructed to rest between test and retest.
Deleted: s

Deleted: plantar fascia

Deleted: to use the windlass mechanism to stretch the plantar fascia

Deleted:

Deleted: plantar fascia

Deleted: scans

Deleted: just

Deleted: Image

Deleted: from

\section{Deleted: if}

Deleted: randomly chosen if

Deleted: if
Deleted: image

Deleted: plantar fascia

Deleted: could

Deleted: plantar fascia Deleted: 0

Deleted: No significant change in the quantitative ultrasound outcomes were expected during the initial and final tests, because subjects were instructed to rest between these tests. 
Ultrasound Measurement of the plantar fascia

Sonogram Analysis

All sonograms were measured using the built-in software in the scanner. PF thickness

measurements were made at the insertion onto the calcaneus. A third person randomly loaded

sonograms onto the screen for examiner 1 and 2 to measure, thereby blinding the observers to which subject they were measuring.

Data Analysis

Statistical analysis was performed using SPSS version 15.0. The dependant measure of PF thickness was calculated using the built-in software in the scanner. Each sequential measurement was arranged in SPSS as a separate variable, and intraexaminer reliability with $95 \%$ confidence intervals (CI) was estimated using two-way mixed-model, consistency-type intraclass correlation coefficients (ICC).

Both examiners were blinded during measurement of the current and previous thickness values. The reliability when using a single measurement was estimated using the first 2 measurement variables and the "single measures" output from SPSS, The reliability when using a mean of 2 measurements was estimated using the first 2 measurement variables and the "average measures" output from SPSS, The reliability when using a mean of 3 measurements was similarly estimated using the first 3 measurement variables and the "average measures" output from SPSS, To determine interobserver reliability, a parallel model (two-way random effect, total agreement) with single measurement and mean values of 2 and 3 measurements was calculated.

Measurement precision was assessed by limits of agreement (LOA) and LOA as a percentage of the mean value $(\mathrm{LOA} \%)$.
Deleted: Image

Deleted: image

Deleted: inbuilt

Deleted: Plantar fascia

Deleted: image Deleted: and

\section{Deleted: inbuilt}

\section{Deleted:}

Deleted: 2

Deleted: to

Deleted: (model 3,1)

Deleted: (model 3,2)

Deleted: ,

Deleted:

Deleted: (model 3,k)

Deleted: ICC 2.1 was calculated using 
Ultrasound Measurement of the plantar fascia

\section{Results}

The sample included in the study consisted of 4 men and 16 women. Mean age was 24.1 (SD 2.6).

Mean body mass index (BMI) was 22.2 (SD 2.1).

Paired t-test shows no significant difference between the right and left PF, $(\mathrm{p}>0.05)$, table 1. Paired t-test shows no systematic difference in thickness between test and retest for observer 1 or observer $2(\mathrm{p}>0.05)$. ICC values show no significant difference in reliability between right and left $\underline{\mathrm{PF}} \underline{\underline{w i c h}}$

Deleted: PF Deleted: plantar fascia Deleted: diameter Deleted: re-test Deleted: PF Deleted: plantar fascia is the reason why the right and left plantar fascias are pooled in the reliability analysis.

Table 1

\section{Intraobserver}

Intraobserver reliability measured by ICC for observer 1 using one sonogram was 0.50 (CI $0.23-$ $0.70)$ and increased to 0.77 ( $\underline{\mathrm{CI}} 0.56-0.87)$ when using the average of three sonograms.

Deleted: image

Deleted: image

Intraobserver reliability for observer 2 using one sonogram was 0.52 (CI 0.09-0.75) and increased to 0.67 ( $\underline{\mathrm{CI}}$ 0.39-0.82) when using the average of three sonograms. When using one sonogram, LOA was $0.8 \mathrm{~mm}$ for observer 1 and 0.9 for observer 2 . LOA decreased to $0.6 \mathrm{~mm}$ (LOA\% of $17.5 \%)$ and $0.8 \mathrm{~mm}$ (LOA\% 20.8) when using the mean of three sonograms, table 2.

$\underline{\text { Table } 2}$

\section{Interobserver}

Interobserver reliability when measuring different sonograms measured by ICC was 0.62 (CI $0.37-$ 0.78 ) and increased to 0.82 (CI $0.65-0.91)$ when using the mean of three sonograms, table 3 . When the observers measured the same set of sonograms, reliability measured by ICC was 0.71 (CI 0.50 $0.84)$ and 0.73 ( $\underline{\mathrm{CI}} 0.55-0.85)$ and increased to 0.89 ( $\underline{\mathrm{CI}} 0.78-0.95)$ and 0.91 ( $\underline{\mathrm{CI}} 0.82-0.95)$

Table 3

\section{Deleted: image}

Deleted: image

Deleted: U

Deleted: image

Deleted: 76 Deleted: one

Deleted: 1

Deleted: two

Deleted: 3

Deleted: 75

Deleted: image

Deleted: 3

Deleted: image

Deleted: image

Deleted: 2

Deleted: image

Deleted: 2 
Ultrasound Measurement of the plantar fascia

Doing a visual inspection of the consecutive ID number plotted against the difference between test and retest, there are no sign of learning effect with decreased difference with increasing ID number. Furthermore a Bland-Altman plot with the difference between test and retest plotted against the 10 11

\section{Discussion}

The purpose of this study was to determine the intra- and interobserver reliability of US assessment of $\mathrm{PF}$ thickness and to investigate improvements in measurement precision when using the mean value of three measurements compared to one. Intraobserver reliability using one sonogram was 0.50 and 0.52 and using the mean of three sonograms intraobserver reliability increased to 0.67 and 0.77 . Interobserver reliability when using one sonogram was 0.62 and increased to 0.82 when using the average of three sonograms. LOA based on intratester reliability shows that changes in thickness that are larger than $0.8 \mathrm{~mm}$ can be considered actual changes in thickness and not a result of measurement error.

A study by Liang et $\mathrm{al}^{12}$ examined the intraobserver reliability of US to assess the thickness of fascia plantaris in 14 patients diagnosed with plantar fasciitis. They showed ICC values of 0.90 ( $\underline{\mathrm{CI}}$ 0.70-0.97). Craig et $\mathrm{al}^{13}$ did a similar study on an unknown number of patients with diabetes and found ICC of 0.89 . Neither Liang et $\mathrm{al}^{12}$ or Craig et $\mathrm{al}^{13}$ reported whether the measurements were done by a blinded observer, how long time there was between test and retest or which ICC model was used. This makes a direct comparison difficult.

Deleted: re-test

Deleted: diameter Deleted: plantar fascia Deleted: PF Deleted: Deleted: diameter Deleted: diameter Deleted: plantar fascia Deleted: PF Deleted: UI Deleted: plantar fascia Deleted: secondly Deleted: image Deleted: image Deleted: image Deleted: image

Deleted: diameter Deleted: 75 Deleted: diameter Deleted: UI Deleted: diameter Deleted: if

\section{Intraobserver reliability}


Ultrasound Measurement of the plantar fascia

Koppenhaver ${ }^{14}$ examined the intraobserver reliability US to assess the thickness of transverses abdominis (TrA) and multifidi (MU) with a study design similar to this. They found ICC values of 0.83 ( $\underline{\text { CI }} 0.67-0.91)$ and 0.79 ( $\underline{\text { CI }} 0.61-0.81)$, corresponding to $15.1 \%$ and $19.1 \%$ Standard Error of the Estimate (SEM), which approximately corresponds to LOA of 0.7 $\mathrm{mm}$ and $0.9 \mathrm{~mm}$. SEM and LOA are comparable if study designs are similar. ${ }^{15}$ Springer et $\mathrm{al}^{16}$ did a similar study where they found a intraobserver SEM of $17 \%$ when measuring the thickness of TrA, corresponding to measurements precision of $1.3 \mathrm{~mm}$. Bjorda ${ }^{17}$ examined intraobserver reliability when measuring the thickness of the tendon from m supraspinatus. They found LOA of $0.4 \mathrm{~mm}$ and a mean value of

\section{Interobserver reliability}

$\mathrm{O}^{`}$ Connor $^{18} \mathrm{did}$ an interobserver study of US measurement of Achilles tendon thickness. They found a LOA\% of $29 \%$. Ying ${ }^{19}$ did a similar study and found interobserver measurement error between 5 observers of $0.9-1.1 \mathrm{~mm}$, which corresponds to a LOA\% of approximately $20 \%$.

It appears that intraobserver reliability of US assessments of human tendon and muscle thickness are between $0.4 \mathrm{~mm}$ and $1.3 \mathrm{~mm}$ when measuring healthy tendons. LOA\% is between 15 and $19 \%$. Interobserver reliability is slightly lower with LOA\% of approximately $20 \%$. We found

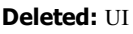

\section{Clinical Relevance}

\begin{tabular}{l} 
Deleted: UI \\
Deleted: diameter \\
\hline Deleted: 35 \\
\hline Deleted: \\
Deleted: \\
\hline Deleted: 3 \\
\hline Deleted: 75 \\
\hline Deleted: \\
\hline Deleted: \\
\hline Deleted: \\
\hline
\end{tabular}




\section{Ultrasound Measurement of the plantar fascia}

Genc et $\mathrm{al}^{26}$ showed a significant correlation between a decrease in thickness of the PF and reduction in pain. This was present at both 1 and 6 months after treatment. They found that PF thickness decreased $1.7 \mathrm{~mm}$ from initial treatment until follow-up at $1 \mathrm{month}$. At the next follow-up after 6 months, the PF thickness had decreased another $0.6 \mathrm{~mm}$. Put into context of the current study, the change in PF thickness that they observed in the first month of treatment reflects actual changes in the thickness. However the change in thickness between 1 and 6 months of follow-up might be caused by measurement error as they only recorded one sonogram. The results of this study showed that if only one sonogram is measured, then the minimal detectable change in PF thickness is

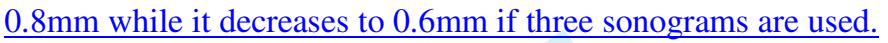

\section{Limitations of ICC}

In order to analyze intra- and interobserver reliability, we used ICC and LOA. ICC is a very common method for describing reliability in different settings. However ICC has some limitations. The size of ICC depends on the ratio of the variability between subjects to the total variability. ${ }^{18}$ This means that the size of ICC may be affected by factors related to the study sample itself. ${ }^{18}$ If two separate test-retest studies are performed on two study samples where one study sample consists of a homogenous group and the other consists of a very heterogeneous groups, the results will be different. This is not because the methods being used have different reliability in the two groups, but because ICC is dependent on the ratio of the variability between subjects to the total variability. ${ }^{18}$ The higher ICC in a heterogeneous group is due to the calculations that ICC is based on and not due to the fact that the methods in the two study samples disagree. The consequence is that it is easier to disguise measurement error in a heterogeneous population. Liang et $\mathrm{al}^{12}$ and Craig et $\mathrm{al}^{13}$ both examined pathological groups that may consist of a more heterogeneous sample. This
Formatted: Superscript

Deleted: plantar fascia

Deleted: plantar fascia

Deleted: could

\section{Deleted: from}

Deleted: plantar fascia

Deleted: re-test

Deleted:

Deleted: group is

Deleted: study sample 
2

3

4

5

6

7

8

9

Ultrasound Measurement of the plantar fascia

may explain why the LOA found in the current study corresponds to other studies, but ICC in the current study is lower than what was reported by Liang et al ${ }^{12}$ and Craig et al. ${ }^{13}$

\section{Comparison of mean thickness of the PF}

The earliest study where the thickness of the Pf was quantified by US was published in $1993 .{ }^{21}$ Studies that examine healthy subjects find mean values of the thickness between 2.6 and $3.9 \mathrm{~mm}_{-}{ }^{7}$, ${ }^{21-27}$ The two largest studies, which included 154 and 110 subjects, found mean thickness of the PF of $3.2 \mathrm{~mm}$ (women and men combined) and $3.3 \mathrm{~mm}( \pm 0.3 \mathrm{~mm})$ for women and $3.9 \mathrm{~mm}( \pm 0.5 \mathrm{~mm})$ for men. The average values in these studies are very similar to the ones found in the present study. Discrepancy in the positioning of subjects, different reference point of measurement and body mass index may to some extent explain the variation from 2.6 to $3.9 \mathrm{~mm}$.

Deleted: The external validity Deleted: plantar fascia Deleted: of mean values of the plantar fascia

Deleted: .

Deleted: diameter

Deleted: plantar fascia

Deleted: UI

Deleted: s

Deleted: diameter Deleted: that

Deleted: diameter

Deleted: plantar fascia Deleted: PF

Deleted: ,

\section{Largest measurement error from scan or measurement}

The results in table 2 and 3 show that the interobserver reliability when both observers measure the same scans is higher than when they measure separate scans. This indicates that scan is a source of error rather than measurement of the scan. The thickness of the PF is not identical across the entire insertion onto the calcaneus. ${ }^{28}$ This means that movement of the transducer might affect the

recorded thickness. Furthermore it indicates that some of the variance across the different scan is not only due to measurement error, but reflects actual changes in thickness.

Deleted: diameter

Deleted: plantar fascia

Deleted: diameter

Deleted: are

Deleted: s

Deleted: diameter

\section{Conclusion}

Measurement of PF thickness by US is a reliable method. If the same observer measures the same person twice, the difference will be maximum 0.6-0.8 mm (ICC 0.67-0.77) in $95 \%$ of the examinations when using the mean of three sonograms. If two different observers examine the same

\begin{tabular}{l} 
Deleted: PF \\
Deleted: plantar fascia \\
Deleted: UI \\
Deleted: two times \\
Deleted: in $95 \%$ of the times \\
Deleted: 3 \\
\hline
\end{tabular}


Ultrasound Measurement of the plantar fascia

subject twice, the measurement error will be maximum $0.6 \mathrm{~mm}$ (ICC 0.82 ) in $95 \%$ of the

Deleted: then in $95 \%$ of the examinations.

examinations

Deleted: imally

Deleted: 57

Deleted:

Deleted: Clinical RelevanceII

The results showed that reliability

increases when using the mean of three

images compared to one. Limits of

agreement based on intratester reliability

shows that changes in diameter that are

larger than $0.63 \mathrm{~mm}$ can be considered

actual changes in diameter and not a

result of measurement error. II 
Ultrasound Measurement of the plantar fascia

\section{Reference List}

1. Fornage BD, Rifkin MD Ultrasound examination of the hand and foot. Radiol Clin North Am 1988; 26: 109-129

2. Cardinal E, Chhem RK, Beauregard CG, et al. Plantar fasciitis: sonographic evaluation. Radiology 1996; 201: 257-259

3. Kannus P, Jozsa L Histopathological changes preceding spontaneous rupture of a tendon. A controlled study of 891 patients. J Bone Joint Surg Am 1991; 73: 1507-1525

4. Martinoli C, Bianchi S, Derchi LE Tendon and nerve sonography. Radiol Clin North Am 1999; 37: 691-711, viii

5. Fornage BD, Rifkin MD Ultrasound examination of tendons. Radiol Clin North Am 1988; 26 : 87-107

6. McPoil TG, Martin RL, Cornwall MW, et al. Heel pain--plantar fasciitis: clinical practice guildelines linked to the international classification of function, disability, and health from the orthopaedic section of the American Physical Therapy Association. J Orthop Sports Phys Ther 2008; 38: A1-A18

7. Wearing SC, Smeathers JE, Sullivan PM, et al. Plantar fasciitis: are pain and fascial thickness associated with arch shape and loading? Phys Ther 2007; 87: 1002-1008

8. Hammer DS, Adam F, Kreutz A, et al. Ultrasonographic evaluation at 6-month follow-up of plantar fasciitis after extracorporeal shock wave therapy. Arch Orthop Trauma Surg 2005; 125: 6-9 
Ultrasound Measurement of the plantar fascia

9. Beggs, I, Bianchi, S, Bueno, A, and et al. Musculoskeletal Ultrasound Technical Guidelines: VI. Ankle. [First edition]. 2010. European Society of Musculoskeletal Radiology. Accesssed 19-8-2010 on www.essr.org/html/img/pool/ankle.pdf

10. Grigg NL, Stevenson NJ, Wearing SC, Smeathers JE Incidental walking activity is sufficient to induce time-dependent conditioning of the Achilles tendon. Gait Posture 2009 2010: 31(1):64-7.

11 Grigg NL, Wearing SC, Smeathers JE Eccentric calf muscle exercise produces a greater acute reduction in Achilles tendon thickness than concentric exercise. Br J Sports Med 2009; 43: 280-283

12. Liang HW, Wang TG, Chen WS, et al. Thinner plantar fascia predicts decreased pain after extracorporeal shock wave therapy. Clin Orthop Relat Res 2007; 460: 219-225

13. Craig ME, Duffin AC, Gallego PH, et al. Plantar fascia thickness, a measure of tissue glycation, predicts the development of complications in adolescents with type 1 diabetes. Diabetes Care 2008; 31: 1201-1206

14. Koppenhaver SL, Parent EC, Teyhen DS, et al. The effect of averaging multiple trials on measurement error during ultrasound imaging of transversus abdominis and lumbar multifidus muscles in individuals with low back pain. J Orthop Sports Phys Ther 2009; 39: 604-611

15. Atkinson G, Nevill A Typical error versus limits of agreement. Sports Med 2000; 30: 375381 
Ultrasound Measurement of the plantar fascia

16. Springer BA, Mielcarek BJ, Nesfield TK, et al. Relationships among lateral abdominal muscles, gender, body mass index, and hand dominance. J Orthop Sports Phys Ther 2006; 36: 289-297

17. Bjordal, JM, Demmink, JH, and Ljunggren AE. Tendon Thickness and Depth from Skin for Supraspinatus, Common Wrist and Finger Extensors, Patellar and Achilles Tendons: Ultrasonography study of healthy subjects. Phys.Ther. 89[6], 375-383. 2005.

18. O'Connor PJ, Grainger AJ, Morgan SR, et al. Ultrasound assessment of tendons in asymptomatic volunteers: a study of reproducibility. Eur Radiol 2004; 14: 19681973

19. Ying M, Yeung E, Li B, et al. Sonographic evaluation of the size of Achilles tendon: the effect of exercise and dominance of the ankle. Ultrasound Med Biol 2003; 29: 637642

20. Norman G The pruning of Doctor McDonough and the "humanizing" of statistics. Fertil Steril 1997; 68: 570-573

21. Wall JR, Harkness MA, Crawford A Ultrasound diagnosis of plantar fasciitis. Foot Ankle 1993; $14: 465-470$

22. Vohra PK, Kincaid BR, Japour CJ, et al. Ultrasonographic evaluation of plantar fascia bands. A retrospective study of 211 symptomatic feet. J Am Podiatr Med Assoc 2002; 92: 444-449 
Ultrasound Measurement of the plantar fascia

23. Pascual HJ, Garcia JM, Matamoros EC, et al. Relationship of body mass index, ankle dorsiflexion, and foot pronation on plantar fascia thickness in healthy, asymptomatic subjects. J Am Podiatr Med Assoc 2008; 98: 379-385

24. Akfirat M, Sen C, Gunes T Ultrasonographic appearance of the plantar fasciitis. Clin Imaging 2003; 27: 353-357

25. Ozdemir H, Yilmaz E, Murat A, et al. Sonographic evaluation of plantar fasciitis and relation to body mass index. Eur J Radiol 2005; 54: 443-447

26. Genc H, Saracoglu M, Nacir B, et al. Long-term ultrasonographic follow-up of plantar fasciitis patients treated with steroid injection. Joint Bone Spine 2005; 72: 61-65

27. Sabir N, Demirlenk S, Yagci B, et al. Clinical utility of sonography in diagnosing plantar fasciitis. J Ultrasound Med 2005; 24: 1041-1048

28. Moraes do Carmo CC, Fonseca de Almeida Melao LI, et al. Anatomical features of plantar aponeurosis: cadaveric study using ultrasonography and magnetic resonance imaging. Skeletal Radiol 2008; 37: 929-935 
Table 1

\begin{tabular}{|l|c|c|c|c|c|c|}
\hline \multirow{2}{*}{ Diameter of fascia plantaris [mm] } & \multicolumn{2}{|c|}{ Men } & \multicolumn{2}{c|}{ Women } & \multicolumn{2}{c|}{ All } \\
\hline & \multicolumn{2}{|c|}{ Mean (SD) } & \multicolumn{2}{|c|}{ Mean (SD) } & \multicolumn{2}{c|}{ Mean (SD) } \\
\hline & Right & Left & Right & Left & Right & Left \\
\hline Diameter observer 1 & $3.93(0.14)$ & $3.82(0.16)$ & $3.44(0.36)$ & $3.45(0.41)$ & $3.55(0.37)$ & $3.49(0.31)$ \\
\hline Diameter observer 2 & $4.03(0.39)$ & $3.93(0.39)$ & $3.54(0.37)$ & $3.58(0.40)$ & $3.63(0.38)$ & $3.67(0.29)$ \\
\hline
\end{tabular}


Table 2

\begin{tabular}{|c|c|c|c|c|c|c|}
\hline $\begin{array}{l}\text { Limits of } \\
\text { agreement (LOA) }\end{array}$ & 1 image & $\begin{array}{c}\% \text { of } \\
\text { observers } \\
\text { average }\end{array}$ & $\begin{array}{c}\text { Mean of } 2 \\
\text { images. }\end{array}$ & $\begin{array}{c}\% \text { of } \\
\text { observers } \\
\text { average }\end{array}$ & Mean of 3 images. & $\begin{array}{c}\% \text { of } \\
\text { observers } \\
\text { average }\end{array}$ \\
\hline Observer $1[\mathrm{~mm}]$ & 0.76 & $21.1 \%$ & 0.67 & $18.6 \%$ & 0.63 & $17.5 \%$ \\
\hline Observer $2[\mathrm{~mm}]$ & 0.91 & $25.3 \%$ & 0.82 & $22.8 \%$ & 0.75 & $20.8 \%$ \\
\hline Interobserver [mm] & 0.67 & $18.6 \%$ & 0.62 & $17.2 \%$ & 0.57 & $15.8 \%$ \\
\hline $\begin{array}{l}\text { Interobserver, both } \\
\text { observers measure } \\
\text { observer 1's scans. } \\
{[\mathrm{mm}]}\end{array}$ & 0.59 & $16.3 \%$ & 0.52 & $14.4 \%$ & 0.47 & $13.0 \%$ \\
\hline $\begin{array}{l}\text { Interobserver, both } \\
\text { observers measure } \\
\text { observer 2's scans. } \\
{[\mathrm{mm}]}\end{array}$ & 0.55 & $15.6 \%$ & 0.49 & $13.9 \%$ & 0.43 & $12.2 \%$ \\
\hline
\end{tabular}




\section{Table 3}

\begin{tabular}{|l|l|l|l|}
\hline Intraclass correlation coefficient. & \multicolumn{1}{|c|}{1 image } & Mean of 2 images & Mean of 3 images. \\
\hline Intraobserver, observer 1 [ICC 95 \% CI] & $0.50(0.23-0.70)$, & $0.73(0.48-0.85)$ & $0.77(0.56-0.87)$ \\
\hline Intraobserver, observer 2 [ICC 95 \% CI] & $0.52(0.09-0.75)$ & $0.64(0.32-0.81)$ & $0.67(0.39-0.82)$ \\
\hline Interobserver [ICC 95 \% CI] & $0.62(0.37-0.78)$ & $0.80(0.60-0.90)$ & $0.82(0.65-0.91)$ \\
\hline $\begin{array}{l}\text { Interobserver [ICC 95 \% CI]. Both } \\
\text { observers measure observer one`s scans. }\end{array}$ & $0.71(0.50-0.84)$ & $0.86(0.71-0.93)$ & $0.89(0.78-0.95)$ \\
\hline $\begin{array}{l}\text { Interobserver [ICC 95 \% CI]. Both } \\
\text { observers measure observer two`s scans. }\end{array}$ & $0.73(0.55-0.85)$ & $0.89(0.79-0.94)$ & $0.91(0.82-0.95)$ \\
\hline
\end{tabular}


Table legends

Table 1: Diameter of the plantar fascia sub grouped by gender as well as combined, shown for observer 1 and 2 .

Table 2: Intra- and interobserver reliability presented as Limits of Agreement (LOA), and LOA as percentage of observers' average diameter based on all measurements.

Table 3: Intra- and interobserver reliability. Values are presented as ICC with $95 \%$ confidence interval. 


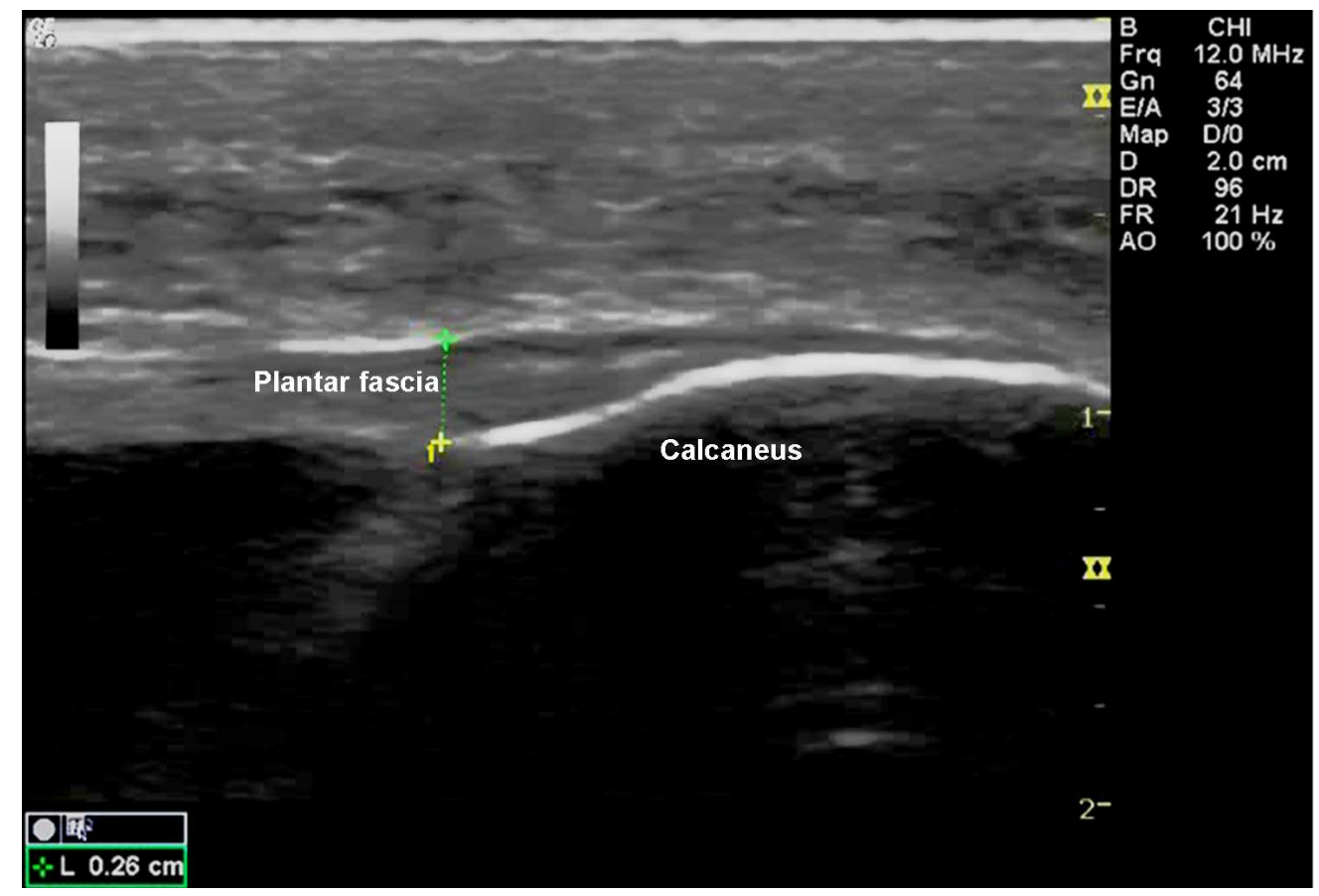

Figure 1 Long-axis sonograms of the plantar fascia at the insertion onto the calcaneus. $254 \times 172 \mathrm{~mm}(150 \times 150 \mathrm{DPI})$ 


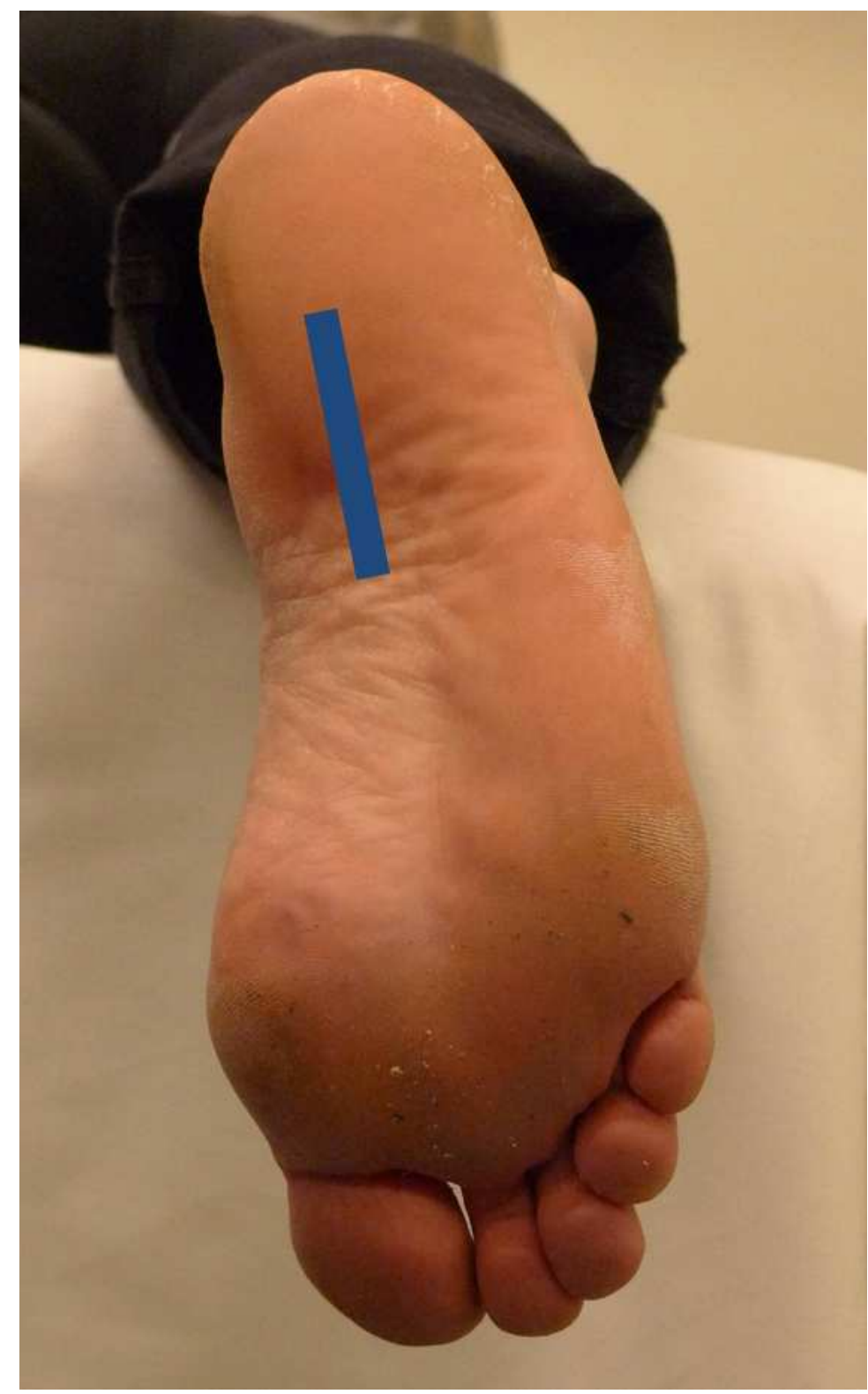

Figure 2 The blue bar on the image indicates placement of the probe on the plantar aspect of the hindfoot. $96 \times 155 \mathrm{~mm}(150 \times 150 \mathrm{DPI})$ 